\title{
Emendation of genus Collinsella and proposal of Collinsella stercoris sp. nov. and Collinsella intestinalis sp. nov.
}

\author{
Akiko Kageyama and Yoshimi Benno
}

Japan Collection of Microorganisms, The Institute of Physical and Chemical Research (RIKEN) Wako, Saitama 351-0198, Japan

\begin{abstract}
Author for correspondence: Akiko Kageyama. Tel: +81484621111 ext. 5132. Fax: +81484624619 e-mail: kageyama@jcm.riken.go.jp
\end{abstract}

\begin{abstract}
Collinsella aerofaciens-like strains isolated from human faeces were characterized by biochemical tests, cell wall murein analysis and 16S rDNA analysis. The results indicated that these strains are phylogenetically a member of the family Coriobacteriaceae and close to the genus Collinsella. Their phenotypic characters resembled those of Collinsella aerofaciens. Determination of DNA-DNA relatedness showed that these strains could be divided into two groups (groups 1 and 2). Collinsella aerofaciens and both new groups have A4-type cell wall murein. Based on their phenotypic and phylogenetic characters, two new species of the genus Collinsella are proposed for the isolated strains: Collinsella stercoris for group 1 and Collinsella intestinalis for group 2. Species-specific PCR primer sets for these two species were also constructed. Using these primer sets, Collinsella stercoris and Collinsella intestinalis can be identified easily and rapidly.
\end{abstract}

Keywords: Collinsella stercoris sp. nov., Collinsella intestinalis sp. nov., 16S rDNA, cell wall, PCR

\section{INTRODUCTION}

Collinsella aerofaciens belongs to the family Coriobacteriaceae and is close to the genus Coriobacterium (Hass \& König, 1988) or Eggerthella (Wade et al., 1999; Kageyama et al., 1999c). In 1971, Moore et al. reported that these organisms belonged to the genus Eubacterium because they are Gram-positive, obligatory anaerobic, non-spore-forming rods which do not produce propionic acid as a major product (Propionibacterium); lactic acid as a sole major acid product (Lactobacillus); large amounts of succinic (in the presence of $\mathrm{CO}_{2}$ ) and lactic acids, sometimes with acetic and formic acids (Actinomyces); or acetic and lactic acids (acetic $>$ lactic), with or without formic acid, as sole major acid products (Bifidobacterium) (Moore et al., 1971). The genus Eubacterium has a broad definition and has over the years acted as a repository for a large number of phenotypically diverse species (Andreesen, 1992). Currently, some species that belonged to the genus Eubacterium have been

The DDBJ accession numbers for the 16S rDNA sequences of Collinsella stercoris JCM 10639-10642 and JCM 10708-10711, and for Collinsella intestinalis JCM 10646 and 10647 are AB030159-AB030162, AB037381, $\mathrm{AB} 037382$, $\mathrm{AB} 037384$ and $\mathrm{AB} 037385$, and $A B 031063$ and $A B 037383$, respectively. transferred to other genera or new genera with specific phylogenetic characters (Kageyama et al., 1999a, b; Ludwig et al., 1992; Wade et al., 1999). In particular, Eubacterium aerofaciens was reclassified on the basis of phylogenetic characters and cell wall peptidoglycan type, and transferred to the new genus Collinsella with one species (Kageyama et al., 1999a). Collinsella aerofaciens is the most abundant bacterium in the human intestine (Benno et al., 1986; Finegold \& Sutter, 1978; Moore \& Holdeman, 1974). However, some strains identified as Collinsella aerofaciens by biochemical tests or morphology were actually new species.

In this paper we report on the phenotypic and phylogenetic characterization of 10 Collinsella aerofaciens-like strains from human faeces. On the basis of the results presented, we propose that these organisms be classified as Collinsella stercoris sp. nov. and Collinsella intestinalis sp. nov. Furthermore, speciesspecific PCR primer sets for these two new species were constructed. Using these primer sets, we can identify the two new species rapidly and easily.

\section{METHODS}

Bacterial strains studied and cultivation. Strains RCA55-4 (JCM 10639), RCA55-5 (JCM 10708), RCA55-27 (JCM 
10709), RCA55-34 (JCM 10640), RCA55-49 (JCM 10710), RCA55-54 (JCM 10641 ${ }^{\mathrm{T}}$ ), RCA55-56 (JCM 10642), RCA55-58 (JCM 10711), RCA56-68 (JCM 10646 ${ }^{\mathrm{T}}$ ) and RCA56-80 (JCM 10647) used in this study were isolated from human faeces. All bacterial strains were cultivated for $2 \mathrm{~d}$ at $37^{\circ} \mathrm{C}$ on EG agar [premixed EG agar (Eiken Chemical) supplemented with $5 \%$ horse blood containing $3 \mathrm{~g}$ beef extract, $5 \mathrm{~g}$ yeast extract, $10 \mathrm{~g}$ peptone, $1.5 \mathrm{~g}$ glucose, $0.5 \mathrm{~g}$ L-cysteine. $\mathrm{HCl}, 0.2 \mathrm{~g}$ L-cystine, $4 \mathrm{~g} \mathrm{Na} \mathrm{HPO}_{4}, 0.5 \mathrm{~g}$ soluble starch, $0.5 \mathrm{~g}$ Tween $80,0.5 \mathrm{~g}$ silicone and $15 \mathrm{~g}$ agar in $1000 \mathrm{ml}$ distilled water; $\mathrm{pH} \mathrm{7.7]} \mathrm{in} \mathrm{an} \mathrm{anaerobic} \mathrm{jar} \mathrm{with}$ $100 \% \mathrm{CO}_{2}$.

Phenotypic characteristics. Acid production from carbohydrates was tested as described previously (Holdeman et al., 1977; Kaneuchi et al., 1976). Activities of 18 enzymes were tested by API ZYM (bioMérieux).

Chemotaxonomy. Cells for chemotaxonomic analyses were obtained from cultures grown in EGF broth [containing $2.4 \mathrm{~g}$ Lab-Lemco powder (Oxoid), $10 \mathrm{~g}$ proteose peptone no. 3 (Difco), $5 \mathrm{~g}$ yeast extract (Difco), $4 \mathrm{~g} \mathrm{Na}_{2} \mathrm{HPO}_{4}, 40 \mathrm{ml}$ sterilized horse blood, $5 \mathrm{~g}$ glucose, $0.5 \mathrm{~g}$ soluble starch (Sigma) and $0.5 \mathrm{~g}$ L-cysteine. $\mathrm{HCl}$ in $960 \mathrm{ml}$ distilled water; $\mathrm{pH} 7 \cdot 6]$ in an anaerobic chamber at $37^{\circ} \mathrm{C}$.

Cell wall peptidoglycan was prepared and hydrolysed by the methods of Kawamoto et al. (1981), and the amino acid composition was analysed with an automatic amino acid analyser (Hitachi; model 835). The neutral amino acid fraction was reacted with a chiral reagent $[(+)-1-(9-$ fluorenyl)ethyl chloroformate] and used for HPLC as described by Einarsson \& Josefsson (1987).

DNA studies. DNA was isolated as described by Saito \& Miura (1983). DNA base composition was estimated by HPLC (Tamaoka \& Komagata, 1984). Levels of DNADNA relatedness were determined by the method of Ezaki et al. (1989) using photobiotin and microplates.

16S rDNA sequencing. Nearly complete $16 \mathrm{~S}$ rDNA gene sequences of all isolated strains were determined. The $16 \mathrm{~S}$ rDNA gene was amplified using the PCR method and prokaryotic $16 \mathrm{~S}$ rDNA universal primers $27 \mathrm{~F}$ (5'-AGAGTTTGATCCTGGCTCAG-3') and 1492R (5'-GGTTACCTTGTTACGACTT-3'). PCR was performed with a DNA thermal cycler (Perkin-Elmer Cetus) using 30 cycles consisting of denaturation at $94{ }^{\circ} \mathrm{C}$ for $60 \mathrm{~s}$, primer annealing at $55^{\circ} \mathrm{C}$ for $150 \mathrm{~s}$ and primer extension at $72{ }^{\circ} \mathrm{C}$ for $150 \mathrm{~s}$ (with $30 \mathrm{~s}$ per cycle added). Sequencing was performed using the ALFred AutoCycle Sequencing kit (Pharmacia Biotech) with an ALFexpress DNA sequencer (Pharmacia Biotech).

Phylogenetic analysis. Species related to the new isolates were determined by performing a sequence database search using FASTA and RDP. The sequence data of related species were retrieved from GenBank. Nucleotide substitution rates ( $K_{\text {nuc }}$ values) were calculated (Kimura \& Ohta, 1972) and phylogenetic trees were constructed by the neighbourjoining method (Saitou \& Nei, 1987). The topology of the trees was evaluated by a bootstrap analysis of the sequence data with CLUSTAL W software (Thompson et al., 1994) (Fig. 1). The DNAML program in the PHYLIP 3.5c package (Felsenstein, 1985) was used for the maximum-likelihood analysis, with the default transition/transversion ratio of 2.000000 (Fig. 2). The sequence similarity values given in Table 4 were determined visually. The DDBJ accession numbers for the $16 \mathrm{~S}$ rDNA sequences of Collinsella stercoris JCM 10639-10642 and JCM 10708-10711, and for Col- linsella intestinalis JCM 10646 and 10647 are AB030159$\mathrm{AB} 030162, \mathrm{AB} 037381, \mathrm{AB} 037382, \mathrm{AB} 037384$ and $\mathrm{AB} 037385$, and $\mathrm{AB} 031063$ and $\mathrm{AB} 037383$, respectively.

Primer design. To design the species-specific primer, we compared 16S rDNA sequences of all isolated strains and Collinsella aerofaciens JCM 10188 ${ }^{\mathrm{T}}$, JCM 7790 and JCM 7791 , and then searched for specific positions. We designed two sets of primers: STER-F and STER-R, and INTE-F and INTE-R. The specificity was evaluated by performing a sequence database search using FASTA and RDP.

PCR reaction. PCR was performed using a DNA thermal cycler with 25 cycles consisting of denaturation at $94{ }^{\circ} \mathrm{C}$ for $60 \mathrm{~s}$, primer annealing at $58^{\circ} \mathrm{C}$ for $150 \mathrm{~s}$ and primer extension at $72{ }^{\circ} \mathrm{C}$ for $150 \mathrm{~s}$ with each of the two sets of primers as mentioned above. The sample DNA was prepared by suspending the cultured colony in distilled water, heating at $100{ }^{\circ} \mathrm{C}$ for $5 \mathrm{~min}$ and then rapidly cooling it down. After PCR, an $8 \mu \mathrm{l}$ aliquot of amplified sample from each PCR tube was electorophoresed through $2 \%$ agarose gel (Sigma) in TAE buffer for $30 \mathrm{~min}$ at $100 \mathrm{~V}$. Amplification products were visualized and photographed under a UV light transilluminator after $30 \mathrm{~min}$ of ethidium bromide staining. The molecular masses of the amplicons were determined by comparison with commercial DNA molecular mass markers.

\section{RESULTS}

\section{Morphological characteristics}

All of the strains which we studied were Gram-positive, non-sporing, anaerobic rods. Colonies were white or grey in the centre with clear margins on EG agar. Cells were $0 \cdot 3-0.5 \times 1 \cdot 2-2.4 \mu \mathrm{m}$ long and occurred in chains of $2-20$ cells.

\section{Biochemical and physiological tests}

The 10 isolated strains of Collinsella aerofaciens-like micro-organisms were characterized. They were divided into two groups: group 1 consisted of eight strains (RCA55-4, RCA55-5, RCA55-27, RCA55-34, RCA55-49, RCA55-54, RCA55-56 and RCA55-58) and group 2 consisted of two strains (RCA56-68 and RCA56-80). Group 1 strains produced acid from glucose, mannose, galactose, fructose, maltose, cellobiose and lactose. None of them produced acid from L-arabinose, D-xylose, rhamnose, ribose, sucrose, raffinose, melezitose, starch, glycogen, mannitol, sorbitol, inositol, erythritol or aesculin (Table 1). They showed strong activity of leucine arylamidase, acid phosphatase, naphthol-AS-BI-phosphohydrolase, $\beta$-galactosidase and $N$-acetyl- $\beta$-glucosaminidase, and weak activity of alkaline phosphatase, $\alpha$-glucosidase and $\beta$ glucosidase. They did not show activity of lipase $(\mathrm{C} 4)$, valine arylamidase, cystine arylamidase, trypsin, chymotrypsin, $\alpha$-galactosidase, $\beta$-glucuronidase, $\alpha$ mannosidase or $\alpha$-fucosidase (Table 2). Group 2 strains produced acid from glucose, mannose, galactose, fructose and cellobiose. None of them produced acid from L-arabinose, D-xylose, rhamnose, sucrose, maltose, lactose, trehalose, raffinose, melezitose, starch, glycogen, mannitol, sorbitol, inositol, 
Table 1. Acid production by Collinsella aerofaciens-like strains and Collinsella aerofaciens

+ , Positive; -, negative; V, variable.

\begin{tabular}{|lccc|}
\hline Acid from: & \multicolumn{2}{c}{$\begin{array}{c}\text { Collinsella aerofaciens- } \\
\text { like strains* }\end{array}$} & $\begin{array}{c}\text { Collinsella } \\
\text { aerofaciens } \dagger\end{array}$ \\
\cline { 2 - 3 } & Group 1 & Group 2 & \\
\hline Rhamnose & - & - & V \\
Ribose & - & V & V \\
Sucrose & - & - & V \\
Maltose & + & - & + \\
Cellobiose & + & + & V \\
Lactose & + & - & + \\
Trehalose & V & - & V \\
Raffinose & - & - & V \\
Aesculin & - & V & V \\
Salicin & V & V & V \\
Amygdalin & V & - & V \\
\hline
\end{tabular}

* Data based on reactions of 10 strains isolated in this study.

$\dagger$ Data based on reactions of 181 strains (Table 1, Kageyama et al., 1999a).

erythritol or amygdalin (Table 1). They showed strong activity of leucine arylamidase, acid phosphatase, naphthol-AS-BI-phosphohydrolase and $N$-acetyl- $\beta$ glucosaminidase, and weak activity of alkaline phosphatase. They did not show activity of lipase (C4), valine arylamidase, cystine arylamidase, trypsin, chymotrypsin, $\alpha$-galactosidase, $\beta$-glucuronidase, $\alpha$ mannosidase or $\alpha$-fucosidase (Table 2).

\section{Chemotaxonomic characteristics}

The structure of the cell wall peptidoglycan of RCA55-54, RCA56-68 and RCA56-80 was determined. In RCA55-54, the peptidoglycan contained, in addition to muramic acid and glucosamine, the amino acids glutamic acid, aspartic acid, ornithine and alanine at a molar ratio of $1: 1: 1: 2$. Ornithine occurred in the $\mathrm{L}$ configuration and aspartic acid in the $\mathrm{D}$ configuration. This indicated that the structural type was the A4 $\beta$-type, (L-Ala)-D-Glu-L-Orn-D-Asp. In RCA56-68 and RCA56-80, the peptidoglycan contained, in addition to muramic acid and glucosamine, the amino acids glutamic acid, lysine and alanine at a molar ratio of $2: 1: 2$. Glutamic acid occurred in the $\mathrm{D}$ configuration and lysine in the $\mathrm{L}$ configuration. This indicated that the structural type was the A $4 \alpha$-type, (LAla)-D-Glu-L-Lys-D-Glu.

\section{DNA base composition and DNA-DNA relatedness}

The DNA base composition of RCA55-4, RCA55-54, RCA55-56, RCA56-68 and RCA56-80 was $61 \cdot 2-64 \cdot 4$ mol\% $\mathrm{G}+\mathrm{C}$ according to the HPLC nucleoside method (Table 3). The levels of DNA-DNA relatedness among these five isolated strains and Collinsella aerofaciens $\mathrm{JCM} 10188^{\mathrm{T}}$ were determined, and the values among RCA55-4, RCA55-54 and RCA55-56 were $83 \cdot 1-88 \cdot 3 \%$ and between RCA56-68 and RCA56-80 were $100-101 \%$. Therefore, these two groups were independent species. There was a low level

Table 2. Enzymic activity of Collinsella aerofaciens-like strains and Collinsella aerofaciens

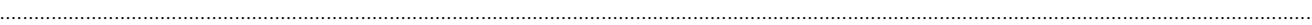

+ , Positive; W, weak; -, negative; V, variable.

\begin{tabular}{|lccc|}
\hline Enzyme & $\begin{array}{c}\text { Collinsella aerofaciens- } \\
\text { like strains* }\end{array}$ & $\begin{array}{c}\text { Collinsella } \\
\text { aerofaciens } \dagger\end{array}$ \\
\cline { 2 - 4 } & Group 1 & Group 2 & \\
\hline Alkaline phosphatase & $\mathrm{W}$ & $\mathrm{W}$ & - \\
Esterase lipase (C8) & - & - & $\mathrm{V}$ \\
Leucine arylamidase & + & + & $\mathrm{W}$ \\
Acid phosphatase & + & + & $\mathrm{W}$ \\
Naphthol-AS-BI-phosphohydrolase & + & + & $\mathrm{V}$ \\
$\beta$-Galactosidase & + & - & $\mathrm{V}$ \\
$\alpha$-Glucosidase & $\mathrm{W}$ & - & $\mathrm{V}$ \\
$\beta$-Glucosidase & $\mathrm{W}$ & - & $\mathrm{V}$ \\
$N$-Acetyl- $\beta$-glucosaminidase & + & + & - \\
\hline
\end{tabular}

* Data based on reactions of 10 strains isolated in this study.

$\dagger$ Data based on reactions of strains JCM 10188 ${ }^{\mathrm{T}}$, JCM 7790, JCM 7791, JCM 10777, JCM 10788 and JCM 10800. 
Table 3. DNA base composition and levels of DNA-DNA relatedness among isolated Collinsella aerofaciens-like strains and Collinsella aerofaciens JCM 10188 ${ }^{\top}$

\begin{tabular}{|lcccc|}
\hline Strain & $\begin{array}{c}\text { G+C } \\
\text { content } \\
\text { (mol\%) }\end{array}$ & RCA55-54 & RCA56-68 & RCA56-80 \\
\cline { 3 - 5 } & & $88 \cdot 3$ & $28 \cdot 5$ & $31 \cdot 4$ \\
RCA55-4 & $63 \cdot 8$ & 100 & $24 \cdot 7$ & $22 \cdot 2$ \\
RCA55-54 & $61 \cdot 2$ & $83 \cdot 1$ & $26 \cdot 7$ & $25 \cdot 7$ \\
RCA55-56 & $63 \cdot 4$ & $22 \cdot 6$ & 100 & 101 \\
RCA56-68 & $64 \cdot 4$ & $18 \cdot 2$ & 100 & 900 \\
RCA56-80 & $63 \cdot 6$ & $8 \cdot 3$ & $8 \cdot 3$ & \\
Collinsella & $60 \cdot 8$ & & & \\
aerofaciens & & & & \\
JCM 10188 & & & & \\
\hline
\end{tabular}

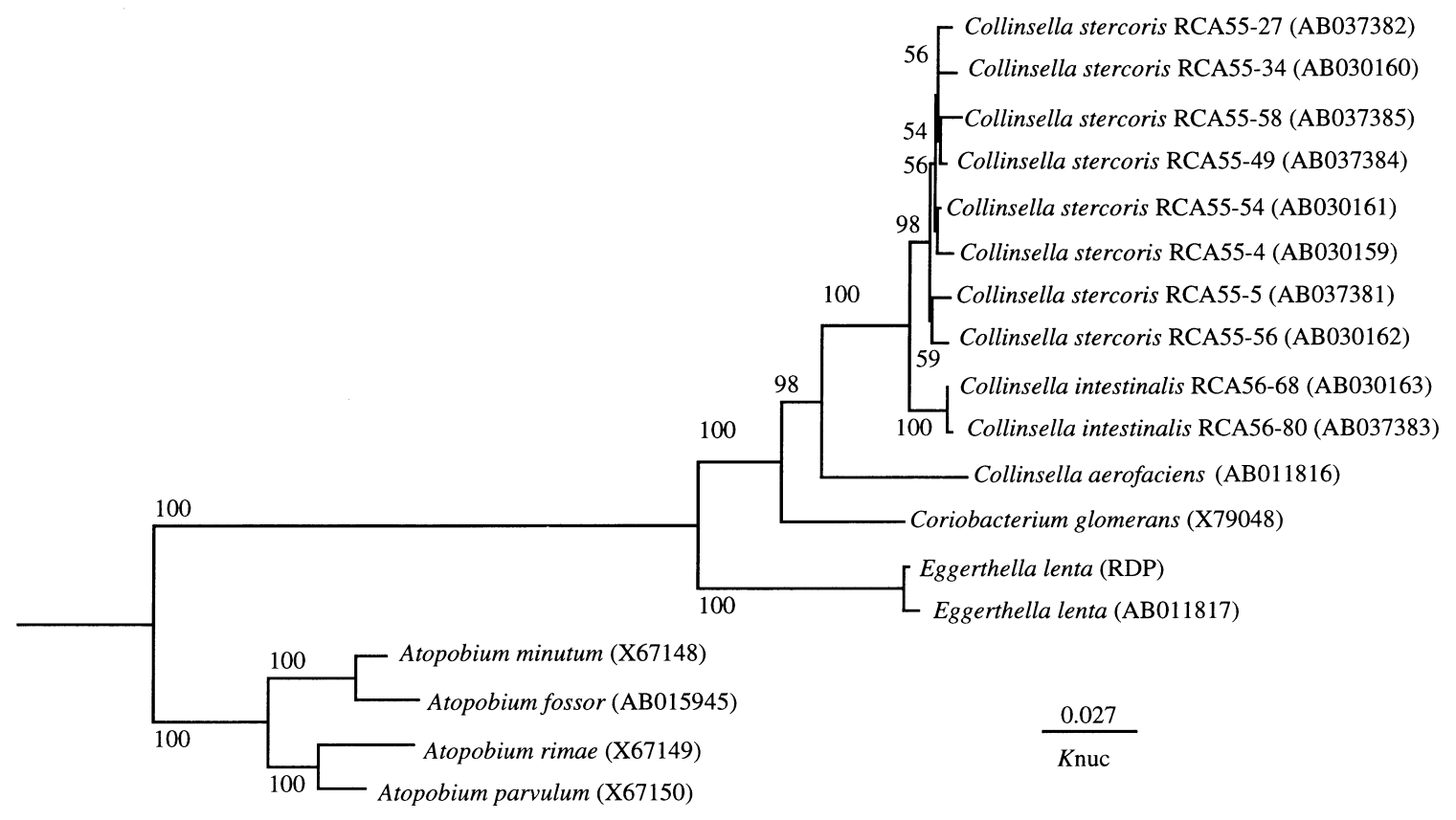

Fig. 1. Phylogenetic tree derived from $16 \mathrm{~S}$ rDNA sequences. The tree was created using the neighbour-joining method and $K_{\text {nuc }}$ values. The numbers on the tree indicate bootstrap values for the branch points. Only values above $50 \%$ significance are indicated.

of DNA-DNA relatedness between the two groups, but it was not enough to assign them to the same species.

\section{S rDNA sequence analysis}

More than 1400 bases of the $16 \mathrm{~S}$ rDNA sequences (positions 28-1491; Escherichia coli numbering system) of all isolated strains were determined, and these sequences have been deposited in the DDBJ database. Fig. 1 shows a phylogenetic tree based on calculated $K_{\text {nuc }}$ values created by using our sequences and those obtained from public databases. Fig. 2 shows a phylogenetic tree based on maximum-likelihood analysis. A database search demonstrated that these isolated strains belong to the family Coriobacteriaceae, which contains the genera Coriobacterium, Atopobium (Collins \& Wallbanks, 1992), Eggerthella and Collinsella. A phylogenetic analysis showed that these isolated strains were closest to Collinsella aerofaciens JCM $10188^{\mathrm{T}}$. The sequence similarity values among these strains are listed in Table 4.

\section{Primer design and specificity}

We compared 16S rDNA sequences of the 10 isolated strains and Collinsella aerofaciens JCM $10188^{\mathrm{T}}$, JCM 7790 and JCM 7791, and designed two sets of 


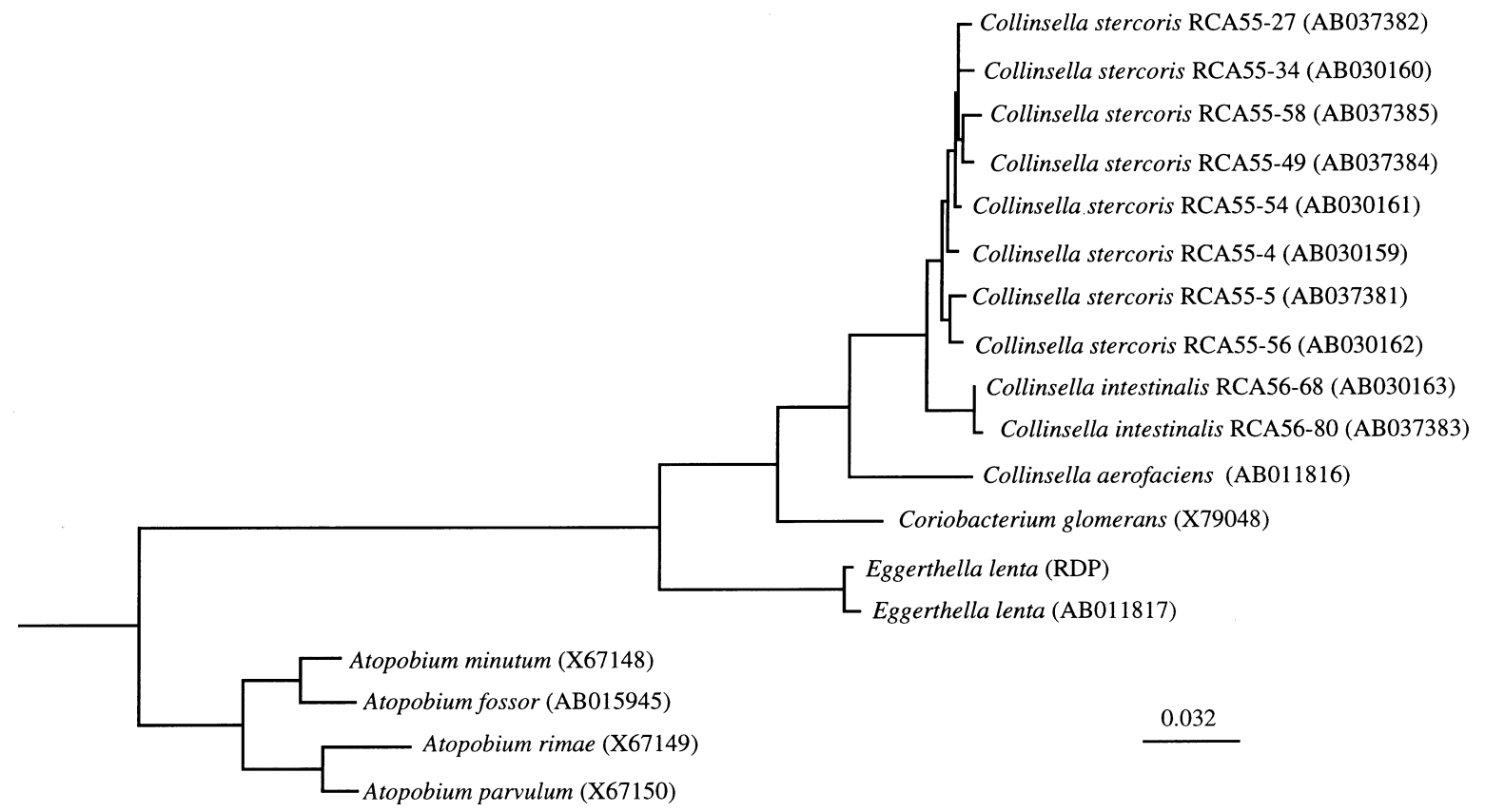

Fig. 2. Phylogenetic tree derived from $16 \mathrm{~S}$ rDNA sequences. The tree was created using maximum-likelihood analysis.

Table 4. Percentage similarity of $16 \mathrm{~S}$ rDNA sequences of isolated Collinsella aerofaciens-like strains and Collinsella aerofaciens JCM $10188^{\top}$

\begin{tabular}{|c|c|c|c|c|c|c|c|c|c|c|}
\hline & 1 & 2 & 3 & 4 & 5 & 6 & 7 & 8 & 9 & 10 \\
\hline 1. RCA55-4 & & & & & & & & & & \\
\hline 2. RCA55-5 & $98 \cdot 5$ & & & & & & & & & \\
\hline 3. RCA55-27 & $98 \cdot 4$ & $99 \cdot 1$ & & & & & & & & \\
\hline 4. RCA55-34 & $98 \cdot 4$ & $98 \cdot 7$ & $99 \cdot 1$ & & & & & & & \\
\hline 5. RCA55-49 & $98 \cdot 8$ & $99 \cdot 0$ & $99 \cdot 2$ & $99 \cdot 0$ & & & & & & \\
\hline 6. RCA55-54 & $99 \cdot 2$ & $99 \cdot 1$ & $99 \cdot 5$ & $99 \cdot 1$ & $99 \cdot 5$ & & & & & \\
\hline 7. RCA55-56 & $98 \cdot 8$ & $99 \cdot 0$ & $98 \cdot 8$ & 98.9 & $98 \cdot 7$ & $99 \cdot 2$ & & & & \\
\hline 8. RCA55-58 & $98 \cdot 2$ & $98 \cdot 6$ & $98 \cdot 7$ & $98 \cdot 7$ & $98 \cdot 9$ & $98 \cdot 8$ & $98 \cdot 4$ & & & \\
\hline 9. RCA56-68 & $96 \cdot 8$ & $97 \cdot 4$ & $97 \cdot 4$ & $97 \cdot 3$ & $97 \cdot 3$ & 97.5 & $97 \cdot 3$ & $96 \cdot 7$ & & \\
\hline 10. RCA56-80 & $96 \cdot 5$ & $97 \cdot 2$ & $97 \cdot 3$ & $97 \cdot 2$ & $97 \cdot 1$ & $97 \cdot 3$ & $97 \cdot 1$ & $96 \cdot 7$ & $99 \cdot 6$ & \\
\hline $\begin{array}{l}\text { 11. Collinsella } \\
\text { aerofaciens } \\
\text { JCM } 10188^{\mathrm{T}}\end{array}$ & $91 \cdot 6$ & $92 \cdot 6$ & 92.5 & $92 \cdot 6$ & $92 \cdot 1$ & 92.5 & $92 \cdot 4$ & $92 \cdot 1$ & $92 \cdot 4$ & $92 \cdot 1$ \\
\hline
\end{tabular}

primers: STER-F (5'-TGCAAGTCGAACGGCACCCG-3') (positions 56-75; Escherichia coli numbering system) and STER-R (5'-CCGTCTGGGCTTTGCCGGCC-3') (positions 223-204), and INTE-F (5'-CTTACCAGGGCTTGACATGA-3') (positions 980-999) and INRE-R (5'-TTAGGCGCCTCCCCCCAGAT-3') (positions 1469-1450). Using primers STER-F and STER-R, a 158 bp amplicon was obtained, and using primers INTE-F and INTE-R, a 486 bp amplicon was obtained. The specificity of the primers was checked by performing PCR with the 10 isolated strains, Collinsella aerofaciens JCM 10188 ${ }^{\mathrm{T}}$, Coriobacterium glomerans JCM $10262^{\mathrm{T}}$ and Eggerthella lenta JCM $9970^{\mathrm{T}}$ (Table 5). STER-F and STER$\mathrm{R}$ were positive only for RCA55-4, RCA55-5, RCA55-27, RCA55-34, RCA55-49, RCA55-54, RCA55-56 and RCA55-58. INTE-F and INTE-R were positive only for RCA56-68 and RCA56-80. 
Table 5. Results of PCR reactions

+ , Positive; -, negative.

\begin{tabular}{|lcc|}
\hline Strains & \multicolumn{2}{c|}{ PCR reaction } \\
\cline { 2 - 3 } & STER-F + STER-R & INTE-F + INTE-R \\
\hline RCA55-4, RCA55-5, RCA55-27, & + & - \\
RCA55-34, RCA55-49, RCA55-54, & & \\
RCA55-56, RCA55-58 & - & - \\
RCA56-68, RCA56-80 & - & - \\
Collinsella aerofaciens $\mathrm{JCM}$ 10188 & - & - \\
Coriobacterium glomerans $\mathrm{JCM}^{\mathrm{T}}$ 10262 & - & \\
Eggerthella lenta $\mathrm{JCM}$ 9970 $^{\mathrm{T}}$ & - & \\
\hline
\end{tabular}

\section{DISCUSSION}

Collinsella aerofaciens is the most abundant bacterium in the human intestine [about $10^{10}$ cells ( $\mathrm{g}$ faeces) ${ }^{-1}$ ], and is found in more than $90 \%$ of human intestines (Benno et al., 1986; Finegold \& Sutter, 1978; Moore \& Holdeman, 1974). This organism has been reclassified on the basis of phylogenetic characters and cell wall peptidoglycan type, and transferred from Eubacterium aerofaciens to the new genus Collinsella with one species (Kageyama et al., 1999a). Moore \& Holdeman (1974) reported that Eubacterium aerofaciens isolated from human intestine could be divided into three main groups (I-III) according to sucrose and cellobiose fermentation patterns. In our previous study, 181 strains of this organism isolated from human faeces over 10 years were divided into four groups (I-IV) on the basis of sucrose and cellobiose fermentation patterns. Three groups, I, II and III, were the same as those of Moore \& Holdeman (1974), and an additional group, IV, was described (Kageyama et al., 1999a).

On the other hand, identification of Collinsella aerofaciens was difficult and required considerable time. Previously, a rapid and easy identification method using species-specific PCR primers for Collinsella aerofaciens was described (Kageyama et al., 2000), and 181 Collinsella aerofaciens-like strains were identified using this method. However, some Collinsella aerofaciens-like strains were not positive for this method. The morphological and biochemical characters of the strains, however, were almost the same as those of Collinsella aerofaciens. We consider that these strains are different species and interesting candidates for study.

The phylogenetic positions of these strains were determined, and some strains were found to be close to Collinsella aerofaciens. The 16S rDNA sequence of all isolated strains was determined. A database search revealed that these strains belong to class Coriobacteriales, family Coriobacteriaceae (Stackebrandt et al., 1997), and are most closely related to Collinsella aerofaciens. Phylogenetic analysis including all species of the family Coriobacteriaceae was performed by two different methods, a neighbour-joining method and maximum-likelihood analysis (Figs 1 and 2, respectively). Both trees showed that the isolated strains are closest to Collinsella aerofaciens. All isolated strains were closely related to each other, but RCA56-68 and RCA56-80 were slightly separated from the other eight strains. The sequence similarity values among the eight strains were $98.2-99.5 \%$, but the sequence similarity values between these eight strains and RCA56-68 and RCA56-80 were 96.5-97.5\%, which is not very high (Table 4). Therefore, we checked the similarity of these strains based on DNA-DNA hybridization. The results showed that the two bacterial groups were both new species (Table 3). Strains RCA56-68 and RCA56-80 (group 2) belonged to one species, and the other strains (group 1) belonged to another species.

It is clear that the isolated strains were divided into two species and that they are related to Collinsella aerofaciens. The phenotypic differential characters of these three species were fermentation of maltose and lactose and activity of $N$-acetyl- $\beta$-glucosaminidase.

Collinsella aerofaciens contains A4 $\beta$-type peptidoglycan and the $\mathrm{G}+\mathrm{C}$ content of the DNA is $60-61$ mol\%. RCA55-54 (group 1) contains A4 $\beta$-type peptidoglycan, and RCA56-68 (group 2) and RCA56-80 (group 2) contain A $4 \alpha$-type peptidoglycan. The $\mathrm{G}+\mathrm{C}$ contents of the DNA are 61-65 mol\% (group 1) and 64-65 mol \% (group 2).

We noted that Collinsella aerofaciens and the two new species have different cell wall peptidoglycan types and phylogenetic characters. However, identification using these differential characters is very difficult and timeconsuming. Therefore, a different, rapid and easy method was required for identification of these microorganisms. Species-specific primers were designed by comparing $16 \mathrm{~S}$ rDNA sequences of the isolated strains and Collinsella aerofaciens. The specificity of these primers was checked by performing PCR with the 10 isolated strains, Collinsella aerofaciens JCM 10188 ${ }^{\mathrm{T}}$, 
Coriobacterium glomerans JCM $10262^{\mathrm{T}}$ and Eggerthella lenta JCM $9970^{\mathrm{T}}$. The results showed that the primer sets were accurate in identification of the two new species.

From phenotypic characters and phylogenetic analysis, it is evident that these two new species belong to the genus Collinsella and we propose the names Collinsella stercoris sp. nov. and Collinsella intestinalis sp. nov.

\section{Emended description of the genus Collinsella (Kageyama, Benno and Nakase)}

Cells occur in chains of rod-shaped cells. Grampositive and obligately anaerobic. Spores and flagella are absent. Fermentation products of glucose are $\mathrm{H}_{2}$, ethanol, formate and lactate. Cell wall contains A4type peptidoglycan. DNA $\mathrm{G}+\mathrm{C}$ content is $60-65$ mol\%. Type species is Collinsella aerofaciens. The genus Collinsella is a member of the Coriobacteriaceae and exhibits a close phylogenetic association with the genus Coriobacterium.

\section{Description of Collinsella stercoris sp. nov.}

Collinsella stercoris (ster'co.ris. L. n. stercus faeces; L. gen. n. stercoris of faeces, referring to the source of the isolate).

Cells are $0.3-0.4 \times 1.3-2.4 \mu \mathrm{m}$ in size and occur in chains of 2-20 cells. Colonies are white or grey in the centre with clear margins on EG agar. Gram-positive and obligately anaerobic. Spores and flagella are absent. Can be cultivated for $2 \mathrm{~d}$ at $37^{\circ} \mathrm{C}$ on EG agar in an anaerobic jar with $100 \% \mathrm{CO}_{2}$. Cells produce acid from glucose, mannose, galactose, fructose, maltose, cellobiose, lactose and salicin, but not from Larabinose, D-xylose, rhamnose, ribose, sucrose, trehalose, raffinose, melezitose, starch, glycogen, mannitol, sorbitol, inositol, erythritol, aesculin or amygdalin. Cells show strong activity of leucine arylamidase, acid phosphatase, naphthol-AS-BI-phosphohydrolase, $\beta$ galactosidase and $N$-acetyl- $\beta$-glucosaminidase, but do not show any activity of lipase (C4), valine arylamidase, cystine arylamidase, trypsin, chymotrypsin, $\alpha$-galactosidase, $\beta$-glucuronidase, $\alpha$-mannosidase or $\alpha$-fucosidase. Cell wall contains A4 $\beta$-type peptidoglycan with an (L-Ala)-D-Glu-L-Orn-D-Asp peptide subunit, and interpeptide bridge consists only of $\mathrm{D}$ Asp. DNA G + C content is $61 \cdot 2 \mathrm{~mol} \%$. Isolated from human faeces. Type strain is JCM $10641^{\mathrm{T}}$ (=DSM $\left.13279^{\mathrm{T}}\right)$.

\section{Description of Collinsella intestinalis sp. nov.}

Collinsella intestinalis (in'test.in.alis. N.L. adj. intestinalis pertaining to the intestine).

Cells are $0.3-0.5 \times 1.2-2.2 \mu \mathrm{m}$ in size and occur in chains of 2-20 cells. Colonies are white or grey in the centre with clear margins on EG agar. Gram-positive and obligately anaerobic. Spores and flagella are absent. Can be cultivated for $2 \mathrm{~d}$ at $37^{\circ} \mathrm{C}$ on EG agar in an anaerobic jar with $100 \% \mathrm{CO}_{2}$. Cells produce acid from ribose, glucose, mannose, galactose, fructose, cellobiose and salicin, but not from L-arabinose, Dxylose, rhamnose, sucrose, maltose, lactose, trehalose, raffinose, melezitose, starch, glycogen, mannitol, sorbitol, inositol, erythritol, aesculin or amygdalin. Cells show strong activity of leucine arylamidase, acid phosphatase, naphthol-AS-BI-phosphohydrolase and $N$-acetyl- $\beta$-glucosaminidase, but do not show any activity of lipase (C4), valine arylamidase, cystine arylamidase, trypsin, chymotrypsin, $\alpha$-galactosidase, $\beta$-glucuronidase, $\alpha$-mannosidase or $\alpha$-fucosidase. Cell wall contains A4 $\alpha$-type peptidoglycan with an (LAla)-D-Glu-L-Lys-D-Glu peptide subunit, and interpeptide bridge consists only of D-Glu. DNA G+C content is $64.4 \mathrm{~mol} \%$. Isolated from human faeces. Type strain is JCM $10643^{\mathrm{T}}\left(=\mathrm{DSM} 13280^{\mathrm{T}}\right)$.

\section{ACKNOWLEDGEMENTS}

We thank M. Chijimatsu for analysis of the cell wall.

\section{REFERENCES}

Andreesen, J. R. (1992). The genus Eubacterium. In The Prokaryotes, 2nd edn, pp. 1914-1924. Edited by A. Balows, H. G. Trüper, M. Dworkin, W. Harder \& K.-H. Schleifer. New York: Springer.

Benno, Y., Suzuki, K., Suzuki, K., Narisawa, K., Bruce, W. R. \& Mitsuoka, T. (1986). Comparison of the fecal microflora in rural Japanese and urban Canadians, Microbiol Immunol 30, 521531.

Collins, M. D. \& Wallbanks, S. (1992). Comparative sequence analyses of the 16S rRNA genes of Lactobacillus minutus, Lactobacillus rimae and Streptococcus parvulus: proposal for the creation of a new genus Atopobium, FEMS Microbiol Lett 95, 235-240.

Einarsson, S. \& Josefsson, B. (1987). Separation of amino acid enantiomers and chiral amines using precolumn derivatization with (+)-1-(9-fluorenyl)ethyl chloroformate and reversedphase liquid chromatography, Anal Chem 59, 1191-1195.

Ezaki, T., Hashimoto, Y. \& Yabuuchi, E. (1989). Fluorometric deoxyribonucleic acid-deoxyribonucleic acid hybridization in microdilution wells as an alternative to membrane filter hybridization in which radioisotopes are used to determine genetic relatedness among bacterial strains, Int J Syst Bacteriol 39, 224-229.

Felsenstein, J. (1985). Confidence limits on phylogenies: an approach using the bootstrap, Evolution 39, 783-791.

Finegold, S. M. \& Sutter, V. L. (1978). Fecal flora in different populations with special reference to diet, Am J Clin Nutr 27, 1456-1469.

Hass, H. \& König, H. (1988). Coriobacterium glomerans gen. nov., sp. nov. from the intestinal tract of the red soldier bug, Int J Syst Bacteriol 38, 382-384.

Holdeman, L. V., Cato, E. P. \& Moore, W. E. C. (1977). Anaerobic Laboratory Manual, 4th edn. Blacksburg, VA: Anaerobe Laboratory, Virginia Polytechnic Institute and State University. 
Kageyama, A., Benno, Y. \& Nakase, T. (1999a). Phylogenetic and phenotypic evidence for the transfer of Eubacterium aerofaciens to the genus Collinsella as Collinsella aerofaciens gen. nov., comb. nov, Int J Syst Bacteriol 49, 557-565.

Kageyama, A., Benno, Y. \& Nakase, T. (1999b). Phylogenic and phenotypic evidence for the transfer of Eubacterium fossor to the genus Atopobium as Atopobium fossor comb. nov, Microbiol Immunol 43, 389-395.

Kageyama, A., Benno, Y. \& Nakase, T. (1999c). Phylogenetic evidence for the transfer of Eubacterium lentum to the genus Eggerthella as Eggerthella lenta gen. nov., comb. nov, Int J Syst Bacteriol 49, 1725-1732.

Kageyama, A., Sakamoto, M. \& Benno, Y. (2000). Rapid identification and quantification of Collinsella aerofaciens using PCR, FEMS Microbiol Lett 183, 43-47.

Kaneuchi, C., Watanabe, K., Terada, A., Benno, Y. \& Mitsuoka, T. (1976). Taxonomic study of Bacteroides clostridiiformis subsp. clostridiiformis (Burri and Ankersmit) Holdeman and Moore and related organisms: proposal of Clostridium clostridiiforme (Burri and Ankersmit) comb. nov. and Clostridium symbiosum (Stevens) comb. nov, Int J Syst Bacteriol 26, 195-204.

Kawamoto, I., Oka, T. \& Nara, T. (1981). Cell wall composition of Micromonospora olivoasterospora, Micromonospora sagamiensis, and related organisms, J Bacteriol 146, 527-534.

Kimura, M. \& Ohta, T. (1972). On the stochastic model for estimation of mutation distance between homologous proteins, J Mol Evol 2, 87-90.

Ludwig, W., Kirchhof, G., Weizenegger, M. \& Weiss, N. (1992). Phylogenetic evidence for the transfer of Eubacterium suis to the genus Actinomyces as Actinomyces suis comb. nov, Int J Syst Bacteriol 42, 161-165.
Moore, W. E. C. \& Holdeman, L. V. (1974). Human fecal flora: the normal flora of 20 Japanese-Hawaiians, Appl Microbiol 27, 961-979.

Moore, W. E. C., Cato, E. P. \& Holdeman, L. V. (1971). Eubacterium aerofaciens (Eggerth) Prevot 1938: emendation of description and designation of the neotype strain, Int J Syst Bacteriol 21, 307-310.

Saito, H. \& Miura, K. (1983). Preparation of transforming deoxyribonucleic acid by phenol treatment, Biophys Acta 72, 619-629.

Saitou, N. \& Nei, M. (1987). The neighbor-joining method: a new method for reconstructing phylogenetic trees, Mol Biol Evol 4, 406-425.

Stackebrandt, E., Rainey, F. A. \& Ward-Rainey, N. L. (1997). Proposal for a new hierarchic classification system, Actinobacteria classis nov, Int J Syst Bacteriol 47, 479-491.

Tamaoka, J. \& Komagata, K. (1984). Determination of DNA base composition by reversed-phase high-performance liquid chromatography, FEMS Microbiol Lett 25, 125-128.

Thompson, J. D., Higgins, D. G. \& Gibson, T. J. (1994). CLUSTAL $\mathrm{W}$ : improving the sensitivity of progressive multiple sequence alignment through sequence weighting, position specific gap penalties and weight matrix choice, Nucleic Acids Res 22, 4673-4680.

Wade, W. G., Downes, J., Dymock, D., Hiom, S. J., Weightman, A. J., Dewhirst, F. E., Paster, B. J., Tzellas, N. \& Coleman, B. (1999). The family Coriobacteriaceae: reclassification of Eubacterium exiguum (Poco et al. 1996) and Peptostreptococcus heliotrinreducens (Lanigan 1976) as Slackia exigua gen. nov., comb. nov. and Slackia heliotrinireducens gen. nov., comb. nov., and Eubacterium lentum (Prevot 1938) as Eggerthella lenta gen. nov., comb. nov, Int J Syst Bacteriol 49, 595-600. 